\title{
Negarawan Sejati Menurut Pandangan Hamka
}

\author{
1. Slamet Faozi, ${ }^{2 \cdot}$ Rahmat Iqbal, ${ }^{3 \cdot}$ Rifky Yulian Syah Bagus Baskoro \\ UIN Raden Intan Lampung Program Pascasarjana \\ 1. $\underline{\text { abukasyfi140815@gmail.com }},{ }^{2}$.rahmatiqbal1357@gmail.com, \\ vikiry17@gmail.com
}

\begin{abstract}
The values of struggle that have been exemplified by the nation's predecessors are costly life lessons. Hamka's capacity as a statesman is very important for his thoughts to appear to the next generation of the country, because Hamka, one of the many national figures owned by Indonesia, is a man known for his strong religious understanding, and is a model of harmony between religion and state. This study uses a qualitative approach that applies a research process to obtain descriptive data results. With this method, it is hoped that the results of this study can provide data and analysis that can represent the theme of the study. Content analysis techniques are used by researchers to draw conclusions that can be imitated or used as a guide by the authors, and the validity of the data by paying attention to its context. Through this technique, the researcher wants to analyze a true statesman according to Hamka as an individual who has a spirit of nationalism and patriotism, which is in accordance with the basic principles of Islam "al-amru bi alma'rūf wa an-nahyu 'an al-munkar'.
\end{abstract}

Keywords: statesman, nationalism, patriotism

\begin{abstract}
ABSTRAK
Nilai-nilai perjuangan yang telah diteladankan oleh para pendahulu bangsa merupakan pelajaran hidup yang mahal harganya. Kapasitas Hamka sebagai negarawan sangat penting untuk dimunculkan pemikirannya kepada generasi penerus bangsa, karena Hamka, salah satu dari sekian banyak tokoh bangsa yang dimiliki oleh Indonesia, pribadi yang masyhūr dengan pemahaman keagamaannya yang kokoh, dan merupakan model keselarasan antara agama dan negara. Penelitian ini menggunakan pendekatan kualitatif yang menerapkan proses penelitian dengan tujuan untuk mendapatkan hasil data yang deskriptif. Dengan metode ini, diharapkan agar hasil dari penelitian ini dapat memberikan data dan analisis yang bisa merepresentasikan tema penelitian. Teknik analisis isi digunakan peneliti untuk membuat simpulan-simpulan yang dapat ditiru atau dijadikan pegangan oleh penulis, dan validitas data dengan memperhatikan konteksnya. Melalui teknik tersebut, peneliti ingin menganalisa negarawan sejati menurut Hamka sebagai individu yang berjiwa nasionalisme dan patriotisme, yang selaras dengan prinsip dasar Islam "al-amru bi al-ma'rūf wa an-nahyu 'an al-munkar".
\end{abstract}

Kata kunci: negarawan, nasionalisme, patriotism 


\section{PENDAHULUAN}

Nusantara tempat lahirnya pribadi-pribadi yang terbentuk dari keragaman kehidupan, berupa suku, bahasa, budaya serta agama. Kenyataan ini sebagai bukti bahwa tokoh-tokoh bangsa yang lahir dari rahim nusantara, bukan hanya unggul dalam keilmuan saja, akan tetapi mempunyai akar kuat pada nilai-nilai kebangsaan. Maksud kebangsaan di sini merupakan fakta dan bukti bahwa keluasan wawasan dan keilmuan seseorang itu selaras dengan luasnya sikap pergaulan, yaitu lingkungan tempat bersosial yang ada, juga ikut membentuk sikap kepribadiannya. Maka, bukan suatu hal yang aneh apabila mereka yang masyhūr di negara ini memahami dengan baik sekaligus menyetujui keragaman lingkungan sekitarnya.

Melalui fakta tersebut, merupakan suatu hal yang penting untuk dipelajari dan diambil pelajaran penting atas sikap perilaku dan dasar-dasar pemikiran para tokoh bangsa. Paradigma ini disadari atau tidak, tentunya akan memberikan pengaruh penting kepada seseorang untuk memiliki simpati akan nilai-nilai kebangsaan. Apabila perasaan peduli akan nilai-nilai kebangsaan telah tumbuh pada diri seseorang, maka bukan suatu hal yang mustahĭl akan muncul pribadi-pribadi di negeri ini yang siap untuk membela dan menjaga tanah air untuk masa depan bangsa dan negara yang baik. Mereka akan meyakini bahwa jiwanya adalah bagian penting atas tanah air tempat tumpah darahnya, yang merupakan rumah tempat tinggalnya. Karena hanya pribadi yang mempunyai rumahlah, yang akan mempunyai kepekaan atas tempat tinggalnya.

Haji Abdul Malik Karim Amrullah atau yang akrab dengan sebutan Hamka, bukan sebatas seorang negarawan dengan kapasitas dan kualitas sebagai tokoh bangsa yang banyak berpengaruh atas dinamika dan pergerakan kehidupan bangsa, serta memiliki andil besar yang pemikirannya disegani secara keilmuan, namun juga memiliki asas yang kokoh dan kuat atas șibgah (identitas) kebangsaan.

Pandangan dan sikap kebangsaan Hamka ini, khususnya yang berhubungan dengan prinsip dan moralitas seorang negarawan akan menjadi fokus utama kajian ini. Selain sebagai pendakwah, Hamka juga ikut dalam dinamika dan pergerakan kenegaraan, dan pemikiran serta uswah hasanah (keteladanan baik) yang telah dicontohkannya merupakan hal penting untuk dijadikan oleh generasi penerus bangsa sebagai sebuah "cermin". 
Paradigma Hamka tentang negarawan sejati digambarkan pada salah satu karyanya yang berjudul "Lembaga Budi", dimana ia menyatakan bahwa tanah air harganya mahal. Sebab itu, seorang yang mencintai tanah airnya maka akan rela menebusnya dengan jiwanya sendiri, dan nilai nyawa akan menjadi murah untuk menebus tanah air, serta mati adalah bukti cinta yang sejati. (Hamka, 2015, hal. 310$311)$.

Semangat kenegarawanan bagi Hamka menjadi faktor utama untuk menghantarkan bangsa menuju kemajuan. Maka, uswah hasanah sebagai negarawan sejati yang telah diteladankan oleh Hamka, diharapkan menjadi salah satu ajakan dan rujukan solutif di tengah krisis sosok figur negarawan dalam konteks negara dan bangsa. Dari latar belakang tersebut, penulis ingin memaparkan pandangan Hamka tentang pola pikir, pola sikap dan tingkah laku seorang negarawan sejati menurut pandangan Hamka.

\section{BIOGRAFI HAMKA}

\section{Hamka: Sosial dan Budaya}

Haji Abdul Malik Karim Amrullah atau yang masyhūr dipanggil Hamka, dilahirkan di desa Kampung Molek, Maninjau, Sumatera Barat, 17 Februari 1908. Hamka adalah salah satu sastrawan Indonesia yang juga ulama dan politikus. Hamka lebih akrab disapa dengan sebutan buya, diambil dari bahasa Arab yaitu abī, abuya yang berarti 'ayahku' atau 'orang yang dihormati'. Penyebutan ini dipakai untuk orang Minangkabau. Ayah Hamka adalah Syekh Abdul Karim bin Amrullah, dikenal sebagai Haji Rasul, merupakan pelopor Gerakan Iṣlāh (tajdīd) di Minangkabau, setelah Hamka kembali dari Mekkah tahun 1906. (Hamka, 2002, hal. 20).

Hamka sebagai tokoh yang multidisipliner, beliau seorang agamawan, politikus, juga wartawan serta penulis. Sebagai seorang agamawan, beliau adalah sebagai salah seorang pendiri organisasi Muhammadiyah. Dinamika pergerakan beliau selalu menjadi sorotan. Karena terlibat kesalahpahaman dengan pemerintah, pada tahun 1960-an saat berpaham Masyumi, Hamka dipenjarakan oleh Soekarno. Selama dalam masa tahanan, Hamka menghabiskan waktunya dengan menulis, dan lahirlah karya tafsīr al-Qur'ān, yaitu Tafsīr al-Azhar yang merupakan karyanya terbesar dan monumental. (Floberita, 2005, hal. 79). 
Sebagai seorang politikus, Hamka pernah berguru kepada H. Oemar Said Tjokroaminoto, Ki Bagus Hadikusumo (Ketua Muhammadiyah 1944-1952) dan beberapa tokoh lainnya, dan pada tahun 1946, Hamka menjabat sebagai Ketua Muhammadiyyah. Hamka memulai kegiatan politik pada tahun 1925, saat menjadi anggota partai politik Sarekat Islam, serta ikut mendirikan Muhammadiyyah di Padang Panjang di tahun yang sama. (Hamka, 2016, hal. iv).

Dalam pernyataannya, Irfan Hamka mengatakan bahwa Hamka bukan hanya seorang ulama, namun juga seorang sasterawan yang sangat produktif di zamannya. Sungguh bias kita hitung dengan jari, di negeri yang mayoritas penduduknya muslim, berapa banyak ulama yang juga seorang budayawan, sastrawan, politisi, dan penulis. Salah satu diantaranya adalah Buya Hamka. (Irfan Hamka, 2017, hal. viii).

Perdana Menteri Malaysia, Tun Abdul Razak mengatakan bahwa Hamka bukan hanya milik bangsa Indonesia, tetapi kebanggan bangsa-bangsa Asia Tenggara. Nama besar Hamka memang tidak hanya terbatas di wilayah nusantara, namun bergema di seluruh penjuru Asia Tenggara. (Floberita, 2005, hal. 79).

Pada bulan Maret 1959, karena kontribusi keilmuan agama Islam di Indonesia, Hamka mendapatkan anugerah yang diberikan dari Majelis Tinggi University al-AzharKairo yaitu gelar Ustāżiyyah Fakhiriyyah (Doctor Honoris Causa). Sejak saat itu Hamka menyandang titel "Dr" di pangkal namanya. Kemudian pada 6 Juni 1974, Hamka juga memperoleh gelar kehormatan dari Universitas Kebangsaan Malaysia pada bidang kesusastraan, dan kemudian mendapatkan gelar Professor dari Universitas Prof. Dr. Moestopo. Semua gelar tersebut diperoleh karena ketekunannya yang tanpa mengenal putus asa untuk senantiasa memperdalam ilmu pengetahuan. (Hamka, 2015, hal xix).

Gajah mati meninggalkan gading, manusia mati meninggalkan nama. Dua bulan setelah mengundurkan diri dari Ketua Umum MUI, Hamka masuk rumah sakit. Kurang lebih setelah seminggu mendapatkan perawatan di Rumah Sakit Pusat Pertamina, pada tanggal 24 Juli 1981, ajal menjemputnya untuk kembali menghadap ke hadirat Illahi pada usia 73 tahun. (Rusydi Hamka, 1983, hal. 230).

Hal yang menarik dari Hamka yang menginspirasi penulis, selain sebagai pujangga, wartawan, ulama, dan budayawan, beliau merupakan negarawan yang memberikan buah pemikiran untuk bangsa dan negara, serta karya-karya yang beliau tinggalkan untuk generasi penerus bangsa merupakan bukti dari hal tersebut. 


\section{Karya-karya Ilmiah Hamka}

Hamka yang berpikiran ke depan selalu mencurahkan berbagai macam karyanya dalam bentuk tulisan. Pemikirannya mencakup berbagai disiplin ilmu, seperti teologi, tasawuf, filsafat, pendidikan Islam, sejarah Islam, fiqh, sastra dan tafsīr. Di antara karya Hamka adalah

a. $\quad$ Falsafah Hidup (1950). Hamka mengawali buku ini dengan memaparkan makna kehidupan. Dalam buku ini, Hamka menjelaskan tentang ilmu dan akal dalam berbagai aspek dan dimensinya. Dibahas di dalamnya, tentang sunnatullah, makna kesederhanaan dan cara hidup sederhana menurut Islam. Hamka juga menjabarkan tentang makna berani dan fungsinya bagi kehidupan manusia. (Hamka, 2016, hal. xiii).

b. Tasawuf Modern (1983). Karya ini pada awalnya adalah kumpulan artikel yang dimuat dalam majalah Pedoman Masyarakat antara tahun 1937-1938 yang selanjutnya dibukukan. Dalam buku ini dijelaskan mengenai tasawuf. Kemudian dipaparkan secara berurutan berbagai pendapat para ilmuwan tentang makna kebahagiaan, bahagia dan agama, bahagia dan utama, kesehatan jiwa dan badan, harta benda dan bahagia, sifat qana'ah, kebahagiaan yang dirasakan Rasulullah saw, hubungan rida dengan keindahan alam, tangga bahagia, celaka, dan munajat kepada Allah swt. (Hamka, 2015, hal. xi).

c. Lembaga Budi (1983). Buku ini membahas tentang akhlak mulia, sebab-sebab yang merusak akhlak, akhlak seseorang yang memegang kursi pemerintahan, akhlak mulia yang seharusnya dimiliki oleh seorang penguasa, akhlak pengusaha, akhlak pekerja, akhlak ilmuwan. Makna yang tersirat dalam buku ini adalah tentang pemikiran Hamka terhadap pendidikan Islam. (Hamka, 2015, hal. xi).

d. Karya Hamka yang paling terkenal dan sangat monumental adalah Tafsīr alAzhar. Tafsīr ini mulai ditulis pada tahun 1962. Isi tafsīr ini sebagian besar penulisannya diselesaikan di dalam penjara, yaitu ketika Hamka ditahan antara tahun 1964-1967. Karya tafsīr ini memiliki daya tarik karena Hamka menggunakan bahasa yang ringan dan mudah dipahami oleh pembaca dari segala lapisan, khususnya adalah kaum awam. Hamka menyengaja untuk menyajikan penjelasannya dengan gaya bahasa yang ringan karena tafsīr tersebut memang disusun untuk kebutuhan masyarakat. (Haidar Musyafa, 2019, hal. 495).

Sebagai seorang pendidik, Hamka telah mampu membuktikan dan meyakinkan keberhasilannya. Meskipun tidak menjadi pendidik dalam arti guru profesional, Hamka 
memancarkan secara keseluruhan sikap sebagai pendidik sepanjang hidupnya, baik melalui bentuk pengajaran langsung maupun melalui tulisan-tulisan dan karya-karyanya.

Dari beberapa karya Hamka di atas, penulis sangat meyakini bahwa hasil pemikiran Hamka merupakan aset mahal bagi generasi penerus bangsa, karena beberapa karya tersebut dapat dijadikan way of life yang jika ditekuni, maka tidak mustahīl akan muncul negarawan-negarawan yang menjadi penerus pemikiran Hamka. Lebih lagi Tafsīr al-Azhar yang jika dipelajari dengan seksama, maka akan menghasilkan generasi muslim yang utuh dan unggul dalam pemahamannya terhadap agama dan kecintaannya terhadap negara.

\section{METODE PENELITIAN}

Penelitian ini menggunakan pendekatan kualitatif, yaitu menerapkan proses penelitian dengan tujuan untuk mendapatkan result dan value data yang deskriptif. Data yang ditemukan akan dikumpulkan baik berupa hasil ucapan, tulisan dan hal-hal serupa terkait lainnya yang memiliki kontinuitas agar dapat diteliti dan diamati secara berkelanjutan. Dengan metode ini, diharapkan agar hasil dari penelitian ini dapat memberikan data dan analisis yang bisa merepresentasikan tema penelitian.

Peneliti menggunakan metode kualitatif deskriptif dalam menganalisa data, yaitu penelitian yang berusaha untuk menjelaskan segala fenomena yang terjadi sehingga dapat memunculkan sebuah teori atau sebuah gagasan baru. Tujuan dari metode ini adalah untuk mendeskripsikan, menjelaskan dan memvalidasi fenomena-fenomena yang terjadi dari objek penelitian. Teknik analisis isi digunakan peneliti untuk membuat simpulansimpulan yang dapat ditiru atau dijadikan pegangan oleh penulis, dan validitas data dengan memperhatikan konteksnya. Melalui teknik tersebut, peneliti ingin menganalisa negarawan sejati menurut pandangan Hamka.

\section{HASIL DAN PEMBAHASAN}

\section{NEGARAWAN SEJATI MENURUT HAMKA}

\section{Hubbu al-wațan min al-īmān}

Hamka dikenal oleh banyak kalangan dari karya-karyanya sebagai agamawan dan negarawan sejati. Setiap pergerakan, Hamka selalu menggunakan sentuhan lembut bagi orang-orang di sekitarnya, termasuk saat menyampaikan dakwah dengan khutbah, karyakarya ilmiah dan dengan perbuatannya. Begitu juga semangat dalam bernegara. 
Tempat seseorang dilahirkan merupakan nikmat Tuhan yang harus dicintai. Bumi ciptaan-Nya ialah tempat seseorang dibesarkan, hasil buminya dimakan, dan air yang mengalir darinya diminum. Apabila seseorang cinta dengan Tuhannya, maka akan tumbuh keinginan yang kuat tentang kecintaannya kepada tanah air dan bangsa. Oleh sebab itu, cinta pada tanah air itu tumbuh karena tauhīd. Karena beriman kepada Allah, maka tumbuhlah rasa cintanya kepada tanah air, nusa dan bangsa. (Hamka, 2016, hal. 196).

Salah satu hal penting yang harus ditanamkan pada diri setiap warga negara, diantaranya cinta tanah air. Sejarah telah membuktikan bahwa kecintaan kepada tanah air adalah sebab yang menjadikan bangsa ini mampu mendeklarasikan kemerdekaan, sehingga bangsa ini memiliki kedaulatan untuk mengatur rumah tangganya, dan mendapatkan pengakuan dari dunia sebagai sebuah bangsa yang merdeka.

Setiap individu yang beriman kepada Allah dan Rasūl-Nya akan mencintai tanah air karena itu sebuah keutamaan. Keimanannya akan menggerakkan dirinya untuk membela tanah air dan bangsanya, mendorongnya untuk berbuat sesuatu untuk kemajuan bangsanya, dan membuatnya terpanggil untuk selalu terdepan dalam membela tanah air dan bangsanya, serta mampu menumbuhkan semangat untuk mengorbankan apa saja yang dimilikinya, bahkan jiwanya dipertaruhkan untuk keutuhan dan kedaulatan tanah air. Dan hanya orang-orang yang beriman, yang mau mencintai tanah air dan bangsanya dengan penuh totalitas. (Hamka, 2015, hal. 93).

Seseorang yang sudah tumbuh rasa cinta terhadap tanah airnya, maka akan tumbuh keberaniannya untuk memberikan dan mengorbankan apa saja demi tumpah darahnya. Karena perasaan cintanya yang dalam terhadap tanah air dan bangsanya, seseorang akan siap untuk hidup menderita bahkan bersedia mati, mengorbankan nyawanya untuk membela harga diri dan martabat banganya dari siapa aja yang berusaha merendahkannya. (Hamka, 2015, hal. 310).

Hamka menjelaskan dalam karyanya "Pelajaran Agama Islam", bahwa dualisme suatu masyarakat terhadap bangsa, yaitu ada yang cenderung untuk lebih mementingkan pribadinya dan ada yang selain memikirkan pribadinya, juga memikirkan kepentingan orang lain, yaitu kepentingan bangsa secara keseluruhan. Menurut Hamka, sikap ini tentu memengaruhi paradigmanya kepada bangsa dan tanah airnya. Apabila seseorang cenderung memilih berpihak kepada orang atau kelompok yang memberikan keuntungan, 
maka perjuangannya hanyalah sebatas untuk memenuhi kepentingan pribadinya. Namun lawan daripada itu, seseorang yang telah mempunyai prasangka baik atas kemajuan bangsa dan tanah airnya, maka akan menjadikan perjuangan dan pengorbanan sebagai dasar kehidupan dan pegangan hidup. Ini dikarenakan founding father adalah golongan yang mempunyai kepedulian atas nasib dan masa depan bangsa dan tanah airnya. Kemerdekaan bangsa adalah harga mati yang wajib untuk diperjuangkan dengan segala resiko. (Hamka, 1996, hal. 432).

Betapa banyak mereka yang mencintai tanah airnya, yang memperjuangkan dengan cita-cita besar, dengan tujuan kebahagian tanah airnya. Namun sebelum citacitanya tercapai, mereka telah menutup mata, tewas dalam perjuangannnya. Mereka merasakan kepuasan dengan kematian itu. Mereka memiliki harapan besar atas pengorbanannya, yaitu kejayaan ibu pertiwi. (Hamka, 2015, hal. 311).

Dalam Undang-Undang Dasar 1945 (UUD 1945) tentang Pertahanan Negara dan Keamanan Negara dijelaskan "tiap-tiap warga negara berhak dan wajib ikut serta dalam usaha pertahanan dan keamanan negara”. (UUD 1945, Bab XII, Pasal 30, Ayat 1).

Nasionalisme Hamka dan kecintaannya kepada tanah air sebagi wujud keimanan yang ada pada dirinya, selalu menjadi pegangan, dicontohkan serta diajarkan oleh Hamka. Bagi Hamka, cinta tanah air merupakan implementasi dari keimanan seseorang. Seseorang dikatakan tidak beriman kepada Allah dan Rasul-Nya, apabila dirinya tidak mempunya kecintaan, rasa peduli dan rasa bangga kepada tanah kelahirannya.

Pemikiran Hamka tentang negara sebagai tumpah darahnya merupakan simbol patriotisme Hamka dengan mencintai tanah tumpah darahnya. Hal tersebut dibuktikan oleh Hamka ketika ikut berjuang mempertahankan kemerdekaan negaranya ketika penjajah Belanda berusaha kembali menjajah bangsa Indonesia. Hamka ikut bersama bergerilya dengan para pejuang di Sumatera Barat. Hamka melakukan hal itu dengan maksud dan tujuan agar kedaulatan bangsa ini tetap terjaga dan tidak kembali jatuh ke tangan kolonial penjajah.

Sampai ajal tiba, kecintaan kepada tanah tumpah darah tetap dipegang erat oleh Hamka. Semua yang dikerjakan berupa dakwah dengan lisan, tulisan maupun perbuatan serta kritikannya adalah karena rasa cinta dan merupakan wujud kepeduliannya kepada tanah airnya, dan dimaksudkan untuk kemajuan dan kejayaan bangsa. Maka tidak dapat diragukan lagi akan kenegarawan sosok Hamka. 


\section{Persatuan dalam Kebhinnekaan}

Bhinneka memiliki pengertian ragam dan beda. Founding father (para pendiri) bangsa menetapkan Bhinneka Tunggal Ika, yang merupakan sebuah falsafah dari Bahasa Jawa Kuno, sebagai moto yang dilekatkan pada simbol kenegaraan Garuda Pancasila karena mereka menyadari akan keragaman budaya, etnik, bahasa, dan agama di negeri ini. (A. Syafi'i Ma'arif, 2015, hal. 37).

Konsep Bhinneka Tunggal Ika sebagai pemersatu bangsa Indonesia, melalui keberagaman beragama, perdamaian, hidup berdampingan secara damai di antara pemeluk agama. Praktek toleransi dilakukan warga negara Indonesia dengan saling menghargai, menghormati atas keberbedaan dalam berpendapat, juga dalam mempercayai agamanya masing-masing. Mereka hidup tidak untuk bermusuhan, melainkan untuk saling berkenalan. Allah berfirman dalam Q.S. al-Ḥjurāt [49] ayat 13 yang artinya:

"Hai manusia, sesungguhnya Kami menciptakan kamu dari seorang laki-laki dan seorang perempuan dan menjadikan kamu berbangsa-bangsa dan bersuku-suku supaya kamu saling kenal-mengenal. Sesungguhnya orang yang paling mulia di antara kamu di sisi Allah ialah orang yang paling taqwa di antara kamu. Sesungguhnya Allah Maha Mengetahui lagi Maha Mengenal”. (Q.S. al-Ḥujurāt [49]: 13).

Hamka adalah salah satu tokoh dan pejuang yang mengajarkan dan meneladankan pentingnya menjaga persatuan dan kesatuan dalam keragaman. Melalui karya Tenggelamnya Kapal Van Der Wijck, Hamka berusaha menjelaskan keanekaragaman suku dalam wadah Negara Kesatuan Republik Indonesia, yang mana merupakan ketetapan Allah swt yang harus disadari dalam konteks mu'āmalah (hablun min an-nās), yaitu hubungan sosial-budaya antar warga negara. (Nunu Burhanuddin, 2015, hal. 374).

Hamka menafsirkan surat tersebut bahwa kita di dunia bukan untuk bermusuhan, melainkan untuk berkenalan. Dan hidup berbangsa-bangsa, bersuku-suku bisa saja menimbulkan permusuhan dan peperangan, karena orang telah lupa kepada nilai ketaqwaan. Islam telah menentukan langkah yang akan ditempuh dalam hidup. Yang semulia-mulia kamu ialah barang siapa yang paling taqwa kepada Allah. Dapat dipahami, bahwa meskipun warna kulit berbeda karena berlainan iklim, benua tempat tinggal pun berlainan, ingatlah bahwa kamu semuanya hanyalah satu belaka, yaitu sama-sama 
manusia yang dipertemukan oleh akal budi. Satu pula Tuhan yang menjadi pengawasanmu siang dan malam yaitu Allah swt. (Hamka, 2015, hal. 171).

Nilai-nilai yang terkandung di dalam konsep Bhinneka Tunggal Ika menurut Tafsīr al-Azhar adalah keberagaman beragama sebagian dari sunatullah, toleransi antar umat beragama, pluralisme dalam kehidupan berbangsa dan bernegara, serta mencintai tanah air yang merupakan sunnah yang diajarkan oleh Nabi Muhammad saw.

Persatuan bangsa menurut Hamka itu terbentuk dari kelompok-kelompok masyarakat terkecil yaitu keluarga. Rumah tangga adalah pusat munculnya persatuan, yaitu tempat mengumpulkan segenap kekuatan yang telah hilang. Dari lingkungan keluarga, maka seseorang akan belajar pokok-pokok keutamaan ummahātu al-faḍail untuk bergaul hidup di masyarakat. (Hamka, 2015, hal. 244).

\section{KESIMPULAN}

Nilai-nilai moral perjuangan yang dicontohkan oleh pendahulu bangsa merupakan pelajaran hidup yang harganya mahal. Generasi penerus bangsa perlu untuk menoleh ke belakang melihat prinsip dan falsafah hidup pendahulu bertujuan menumbuhkembangkan semangat kebangsaan dan cinta tanah air yang sudah mulai terkikiskan oleh perkembangan zaman. Apabila hal tersebut ditinggalkan, maka majunya bangsa akan jauh dari nilai-nilai dasar yang telah digariskan.

Hamka sebagai negarawan, sangat penting untuk dimunculkan pemikirannya kepada generasi penerus bangsa, karena Hamka merupakan salah satu dari tokoh bangsa yang dimiliki oleh Indonesia. Indonesia dengan jumlah penduduk muslim terbesar di dunia, sosok Hamka merupakan pribadi yang masyhūr dengan pemahaman keagamaannya yang kokoh, dan sebagai model ideal keselarasan antara agama dan negara. Agama sebagai ruh pergerakan dan perjuangan, dan menjadi landasan dalam mengisi kemerdekaan. Negara menjadi penopang untuk mewujudkan keamanan dalam memeluk agama dan menjalankan peribadatan. Agama dan negara merupakan satu kesatuan utuh seperti dua sisi mata uang yang saling melengkapi, tidak dapat terpisahkan satu dengan lainnya

Negarawan sejati menurut pandangan Hamka adalah individu yang berjiwa nasionalisme dan patriotisme, yang selaras dengan prinsip dasar Islam al-amru bi alma 'rūf wa an-nahyu 'an al-munkar. Setiap warga negara memiliki tanggung jawab untuk 
terus mempertahankan kedaulatan bangsa dan negara sesuai dengan kapasitasnya masing-masing. Kesadaran setiap warga negara untuk menjaga marwah (kehormatan) bangsa merupakan prinsip hidup, dan cita-cita perjuangan serta harga mati yang tidak bisa ditawar.

\section{DAFTAR PUSTAKA}

Aning S., Floriberta. 2005, 100 Tokoh yang Mengubah Indonesia, cet. 1, Yogyakarta: NARASI.

Burhanuddin, Nunu. 2015, "Kontruksi Nasional Religius Relasi Cinta dan Harga Diri dalam Karya Sastra Hamka”, Jurnal Epistemé, Vol. 10, No. 2.

Hamka, Irfan. 2017, Ayah; Kisah Buya Hamka, Jakarta: Republika.

Hamka, Rusydi. 1983, Pribadi Pribadi dan Martabat Buya Prof. Dr. Hamka, cet. 2, Jakarta: Pustaka Panjimas.

Hamka. 1996, Pelajaran Agama Islam, Jakarta: Bulan Bintang. . 2002, Pengaruh dalam Gerakan Pembaruan Islam di Minangkabau pada Awal Abad ke-2, Jakarta: Theresia Slamet. . 2015, Lembaga Budi, Jakarta: Republika. . 2015, Tafsīr al-Azhar, Juz 4, Jilid 2, Jakarta: Gema Insani. .2015, Tasawuf Modern, Jakarta: Republika. . 2016, Falsafah Hidup, Jakarta: Republika. . 2016, Pandangan Hidup Muslim, Jakarta: Gema Insani.

Ma'arif, A. Syafi'i. 2015, Fikih Kebhinnekaan, Bandung: Mizan Pustaka.

Musyafa, Haidar. 2019, Memahami Hamka; The Untold Stories, cet. 1, Tangerang: Imania.

Undang-Undang Dasar 1945, BAB XII tentang Pertahanan Negara dan Keamanan Negara, Pasal 30, Ayat 1. 